\title{
Incidence of cancer in Fallujah above 10 years age with over view of common cancers in 2011
}

\author{
Abdulwahab A. R. Al-Faluji ${ }^{1^{*}}$, Salih Hussein Ali ${ }^{1^{*}}$, Arkan A. Jasem Al-Esawi ${ }^{2}$ \\ ${ }^{1}$ Fallujah Hospital, Anbar, Iraq; ${ }^{*}$ Corresponding Authors: a_w_alfaluji@yahoo.com, salihhossain@yahoo.com \\ ${ }^{2}$ Pathology Department, Collage of Medicine, Anbar University, Anbar, Iraq
}

Received 26 June 2012; revised 27 July 2012; accepted 10 August 2012

\begin{abstract}
Background: Cancer is a major health problem all over the world, the main obstacle facing cancer prevention is a lack of epidemiological studies to guide local or international efforts for disease control. Aims of the Study: To determine the incidence and pattern of cancer cases above 10 years old, assess the trends during the period of 2011 in Fallujah City. Methods: This is a descriptive study based on collecting of all cancer cases above 10 years old in Fallujah district of Al-Anbare Province (Governorate) during the period between 1st of January 2011-31st of December 2011, new cases of males and females who were diagnosed with any type of cancer excluding leukemia which was referred and treated in different centers outside of AlAnbare Governorate. Results: The incidence of cancer in Fallujah is 96 per 100,000 . The most common cancers in the whole population irrespective of sex were carcinoma of the breast, lung, stomach and colorectal cancers. The most common cancers in females were those of breast, ovary and uterus, comparative finding in males were lung, stomach and bladder cancers. Conclusion: The incidence of cancer in Fallujah appears to be higher than the other regions in Iraq and other Middle East countries, the overall pattern of cancer is however similar to the finding in other countries. Carcinoma of the breast, lung, stomach and colorectal are the leading cancers in Fallujah.
\end{abstract}

Keywords: Fallujah; Cancer; Incidence; Epidemiology

\section{INTRODUCTION}

Cancer is the main cause of death in many countries
[1,2], and it's a major public health problem all over the world [3].

This is the first study of cancer in Al-Fallujah City after USA army invasion at 2003, as congenital malformation and infant mortality were been studied and showed increasing incidence [4].

Generally speaking, cancer is characterized by uncontrolled growth and spread of abnormal cells that formed from the normal cells of the body either spontaneously or through the action of an external chemical carcinogens or mutagenic radiation [5].

Recent reports have drawn attention to increase in congenital birth anomalies in Fallujah blamed on teratogenic, genetics and genomic stress that result from environmental damage by the contamination following the battles in the town in 2004, 2005 [4,6,7].

Epidemiological studies in Fallujah where carried out on congenital birth defects and infant mortality for the last few years and reported some increase in these indicators [6,7]. Regardless of whether this increase in Fallujah is real or artificial, the reported cases do not represent the real situation because of primitive registration system.

\section{METHODS AND SUBJECTS}

This is a descriptive study conducted between (1st of January 2011 to 31st of December 2011) and ethical approval was granted by the scientific committee in Fallujah Hospital.

Fallujah is one of the major eight districts of Al-Anbare governorate which is the largest governorate in Iraq (about one third of Iraqi surface area) located in the west of Iraq with a total population of 1.5 millions (Figures 1 and 2).

Fallujah Region is located in the east of Al-Anbare Governorate, in 2011 the population of Fallujah was estimated at about 600,000 based on 2009 census with an adjusted growth rate of $3 \%$, population were distributed in 3 sub districts in addition to the center of the city (Table 1). 


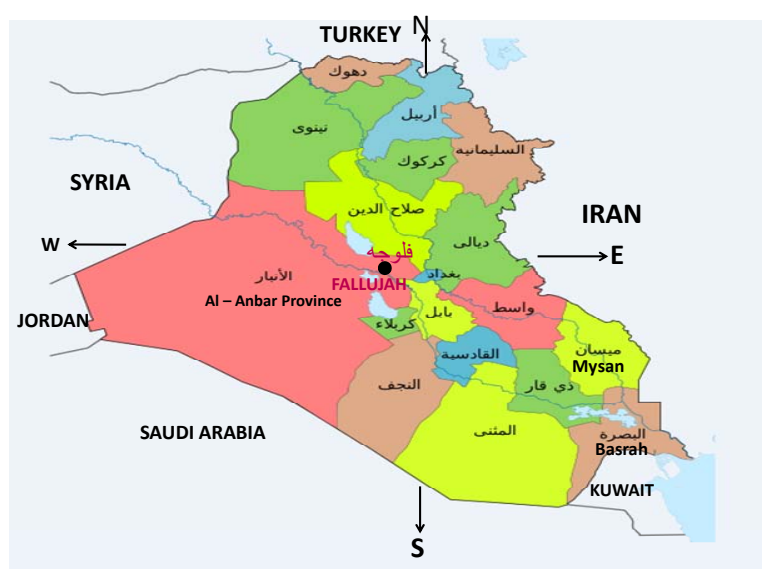

Figure 1. Map of Iraq.

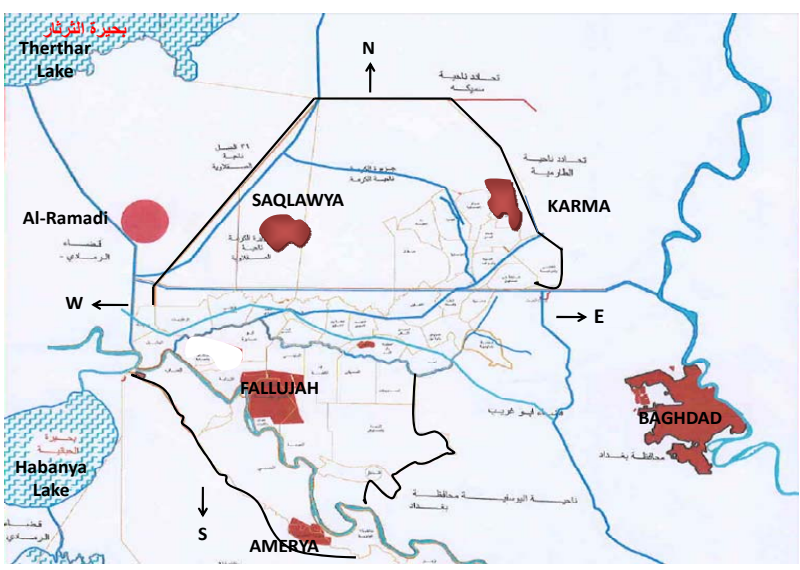

Figure 2. Map of Fallujah and its subdistricts.

Table 1. Registered cancer cases and incidence rate per 100,000 during 2011.

\begin{tabular}{|c|c|c|c|c|c|}
\hline Subdistricts & $\mathrm{N}$ (above $10 \mathrm{y}$ ) population & $\%$ & Cancer cases & Cancer \% & Cancer cases 100000/population \\
\hline Fallujah Center & 212,310 & 51.72 & 272 & 69 & 128 \\
\hline Karma (Eastern area) & 89,666 & 21.85 & 45 & 11.4 & 50.1 \\
\hline Saqlawya (Western area) & 35,368 & 8.61 & 29 & 7.4 & 82 \\
\hline Total & 410,485 & 100 & 394 & 100 & \\
\hline
\end{tabular}

The results reported by this study are based on all cases of cancer above age of 10 years which were diagnosed and registered in Fallujah during the year of study (2011).

\subsection{Health Services in Fallujah Includes:}

1) Down town (center) had Fallujah general hospital of 350 beds, one private hospital (Aljanabi Hospital) of 50 beds, 10 primary health centers, about 100 private clinics and one private histo-pathological lab.

2) Amerya sub district which located in south of Fallujah had general hospital (50 beds), 5 primary health centers and about 20 private clinics.

3) Karma sub district which located in east of Fallujah had 5 primary health centers and about 25 private clinics.

4) Saqlawya sub district which located in west of Fallujah had 5 primary health centers and about 20 private clinics.

\subsection{Inclusion Criteria}

All new cancer cases who were diagnosed and registered at 2011 and above age of 10 years were entered in this study.

\subsection{Exclusion Criteria}

Leukemia and cancer cases below age of 10 years old were excluded from the study.

\subsection{Data Collection Based on}

1) Patients visited or admitted to Fallujah hospital, Al-Janabi private hospital, Amyrea hospital and other primary health centers in down town and its 3 sub districts.

2) Histopathalogical lab. Reports, there is only one histopathology laboratory in Fallujah and its sub districts that managed by one histopathalogist specialist (Dr Arkan A. Jasem).

3) Private clinics of different specialties (more than 100 private clinics in the center and about 20 in each sub districts).

4) Oncology center in Al-Ramadi (capital of Al-Anbar province) which is the only oncology center that received the cancer cases whose residence in Fallujah except leukemia for treatment.

All above mentioned data were registered in a computer system which does not accept duplication names.

Diagnosis of cancer was based on histopathalogical reports of malignancies and was categorized according to system or organ that affected.

The results reported by this study are based on all cases of cancer above age of 10 years which were diagnosed and registered in Fallujah during the year of study (2011).

Information related to population was based on data from the statistical office in Fallujah, after excluding 
pediatrics age group below 10 years age (27.2\%), the total population that included in the study was 410,485 (Denominator) Table 1.

\section{RESULTS}

Approximately male and female are equally affected by malignancies (1:1) and the median age at diagnosis was 60 years for both male and female (Figures 3 and 4).

The incidence rates were calculated as following:

All new cancer cases above 10 years old excluding leukemia cases, denominator was all population of the city (center and 3 sub districts) of 600,000 minus pediatrics age group below 10 years $(189,515) 27.2 \%$ of total population.

The mean age at diagnosis was $52 \mathrm{SD} \pm 18.34$, 95\% confidence interval of 2 SE is 20.18 - 16.5 .

The overall incidence rate for all cancers combined was 96 per 100,000, among males was 92.6 and 99.4 per 100,000 among females (Figure 4).

Geographical distribution: The highest rate of cancer

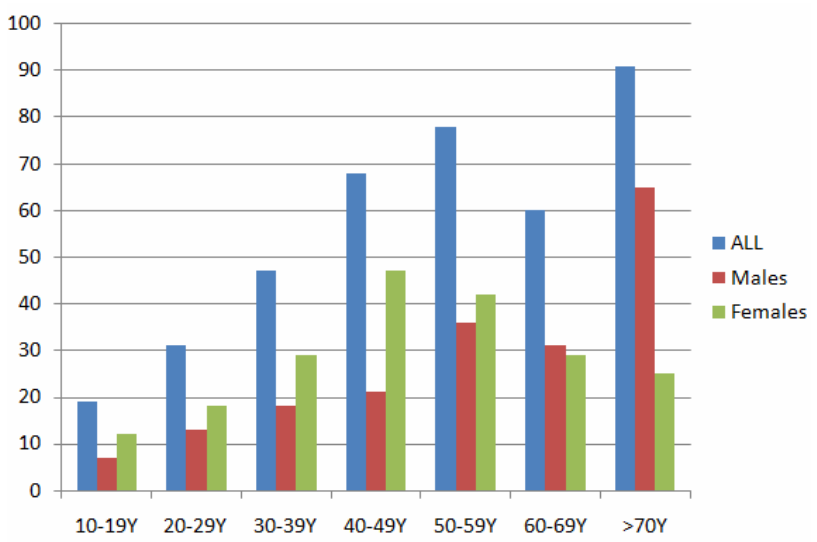

Figure 3. Distribution of registered cancer cases during 2011 according age-specific group.

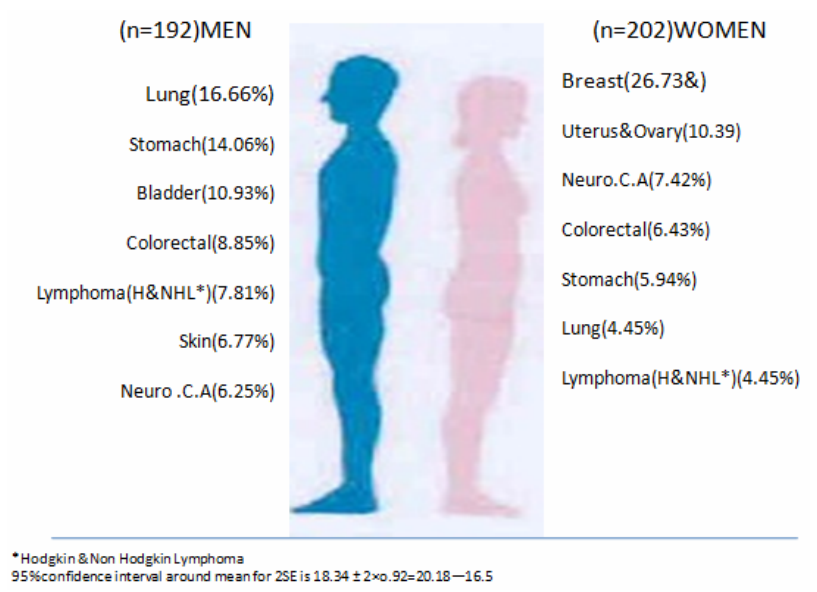

Figure 4. Most commonly occurred cancers in males and females in 2011. was in center of the city $(128$ case per 100,000$)$ followed by western region (Saqlawya) (82 case per 100,000) and lowest rate was in eastern region (karma) (50 case per 100,000) (Figure 5).

The incidence of cancer was directly proportional with age, about $75.5 \%$ of cancer cases was above 40 years age with a peak at the age $>70$ years (Figure 3 ).

In 2011 breast cancer was the most commonly diagnosed cancer in Fallujah (13.7\%) representing 1 in 7 for the entire cases load for all cancers, lung cancer was the second most commonly diagnosed and it was (10.4\%) followed by stomach (9.9\%), colorectal (7.6\%) and bladder $(7.1 \%)$ of cancers. Cancers with unknown primary (secondary) constituted about (3.3\%) of the total case load in 2011 (Figure 6).

The five most frequently registered cancer site in male and female in 2011 are summarized in Figure 4, that shows the following: in males the most common primary site were lung (16.6\%), stomach (14\%) and bladder (11\%) while in females, breast (26.7\%), gynecological (ovary and uterus) was (10.4\%) and neuro-cancer (brain and spinal cord) was (7.4\%) (Figure 4).

The median age of lung cancers in males was (64 years), while the median age of breast cancers in females was (46 years).

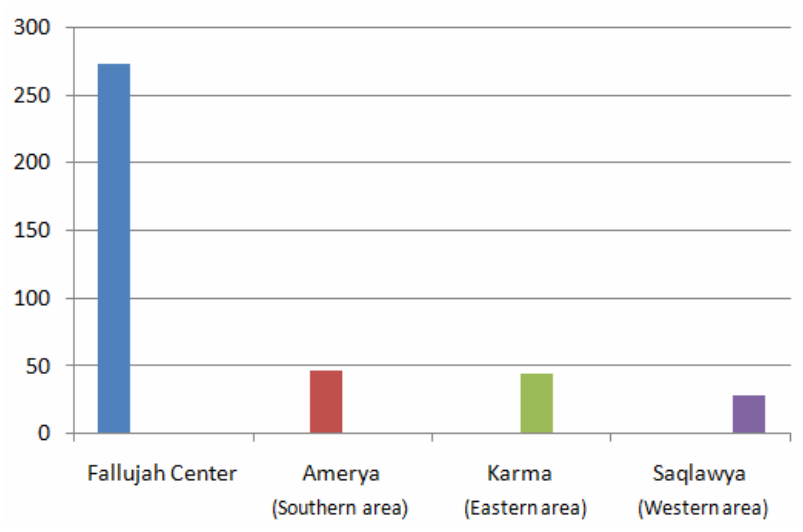

Figure 5. Distribution of registered cancer cases according locality.

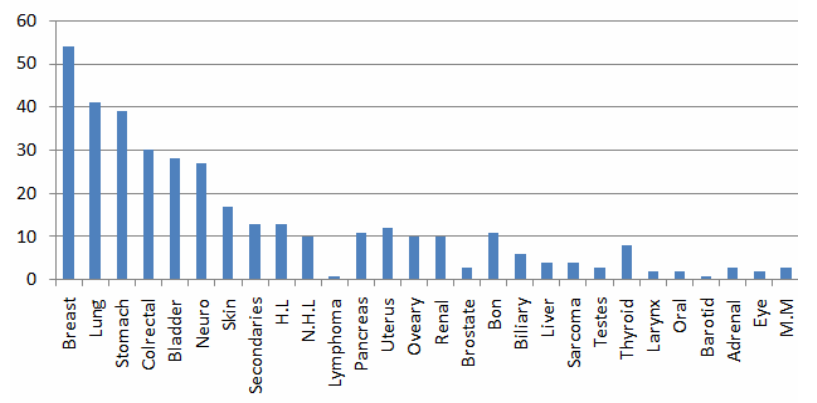

Figure 6. Distribution of registered cancer cases according type of cancer. 


\section{DISCUSSION}

This is the first report concerning cancer incidence in Fallujah Region, although this study deals with a small number of cases, we believe it shed some light on the pattern of common cancers in this region.

Age distribution of all cancers represents that by increasing the ages, the incidence rate increases that's similar to other study in the south of Iraq $[5,8]$ and in the Middle East [2], this may reflect long term changes in the life style and prevalence of risk factors coupled with an increase in life expectancy.

The incidence of all cancer cases in Fallujah in our study (2011) was 96 per 100,000 population which is about three folds higher than what has been registered at 2002 before Iraq invasion (34.5 per 100,000 population) [9], this may reflect some developments in registration system, or increase incidence which may related to same factors that lead to increase in congenital anomalies and infants mortality in Fallujah post USA attack which proved to be radiation effects [4-7].

The annual number of cancer cases In Iraq at 2002 (before Iraq invasion) was 63 per 100,000 of population which is double folds of cancer incidence in Fallujah City at that time (34.5 per 100,000 population), that may related to high incidence of cancers in southern area of Iraq after the first gulf war at 1991 which proved to be due to radiation effects $[5,9]$.

Cancer incidence was higher in Fallujah Center (128 per 100,000 population) than in its sub districts (Saqlawya 82/100,000, Amyria 66/100,000 and Karma 50/ $100,000)$ this is probably due to exposure of Fallujah center to more military operations and battles than its sub districts (first and second Fallujah battles, siege and invasions by USA Army at 2004, 2005).

The incidence of all cancers in Fallujah excluding pediatric age (below 10 years) and leukemia is higher than what was published in Asia (91 - 103 per 100,000 for males and females in Pakistan) [10,11], but lower than in Western European countries (420.9 per 100,000 for males) [12].

In other gulf countries, in Iran (98 - 110 per 100,000 among females and males) [2], in Qatar it was $63.1 \mathrm{per}$ 100,000 [3], south of Iraq (Basra it was 53.1 - 62.8 per $100,000[5,13]$, while incidence of cancer in Jordan was 67.1 per 100,000 [5] and in northern of Saudi Arabia (Aljouf) province is very low incidence (38.5 per 100,000) [14], which is lower than Saudi Arabia national average of 71.7 per 100,000 and lower than the lowest published international figures of 39.6 per 100,000 from Gambia (Africa) [14,15], in comparing these data with our study cancer incidence is higher in Fallujah after adding leukemia and pediatrics cancers below age of 10 years.

The most common cancers in our study irrespective of sexwere carcinoma of breast, lung, stomach and colorectal cancers.

In Fallujah Region as with many other Arab countries, the breast cancer ranks first among malignant neoplasm affecting females [1], the mean age is 46 years, this figure is lower than that observed in developed countries but similar to Iraqi and other developing countries in the region except Israeli Jews [2,5,14,16-18] (between 57\% $68 \%$ of all breast cancers in the Arab population, Egypt, Jordon and Israel where diagnosed before the age of 55 years).

While in Israel Jewish population and Western European countries breast cancer appears to affect older age women [18,19], this is mostly due to difference in environmental risk factors and life expectancy.

The second frequent cancer in females is gynecological cancers (ovary and uterus) which is similar to tago study in Africa [15], while in the Middle East countries (Lebanon, Jordan) the second common cancer in females was colorectal cancer [16,20].

Lung cancer is the commonest one in male that's similar to Eastern province of Saudi Arabia [21,22], and southern area of Iraq (Basra 10.7\%) [4], also similar to Eastern European countries (22\%) [12], but higher than in northern Saudi Arabia (4.2\%) [14].

While the most common cancer among Iranian men was stomach cancer (15 per 100,000) [1]. And most common cancer in Jordanians is colorectal cancer accounting for $14.5 \%$ of all cancers [22].

Gastric cancers incidence is the second to lung cancer (9.9\%), high risk area are East Asia, South America and Eastern Europe [23] The incidence rate was twice as high in males as in females [24], and the highest one in the world was in Japan (77.9 per 100,000) in men and (33.3 per 100,000$)$ in women $[23,24]$. Our study rate is comparable to Israeli Jews (8.5\%) but higher than neighboring countries, Jordanians (4.8\%), Israel Arab (4.6\%), Saudi Arabia national average (3.7\%). Egypt has the lowest incidence in the region (2.9\%) [25].

The overall colorectal cancer in our study is (7.4\%) and in male was (8.8\%) which is similar to other Middle East studies (Lebanon 8.6\%, Jordan and Israel Arab approximately 9\%) [16,18,25], while in European countries and Israeli Jewish the colorectal cancer is the second most frequent cancer (12\% - 14\%) [12] this is related mostly to early detection by screening programs.

In conclusion, Cancer is a growing problem worldwide, still etiology of many types of cancers is absecured, in Fallujah a number of researchers carried out research work on congenital malformations and infant mortality and they reported some increase in both of these indicators, however the apparent increase could have been artificial due to better diagnosis, improved reporting and registration or reflect changes in population. 
Because there are no national programs for screening of prostate, colorectal or breast cancers therefore the incidence of these cancers might be more than these registered data. In addition and due to social customs, many Arab women don't present them self for regular medical examination and this usually result in late presentation.

\subsection{The Limitations of the Study Are}

1) Difficulties in registration of cancer cases below age of 10 years old and leukemia patients as patients referred to capital of Iraq (center for treatments of these cancers not available in Al-Anbar Governorate).

2) Financial limitations as the study were done by personal efforts.

3) Data collection based on hospitals record, private clinics, histopathology lab and oncology center that make cancer cases under estimated as some cases may not reach medical facilities.

\subsection{From This Study We Could Conclude}

1) There is increase in cancer rates in Fallujah (three folds) after USA invasion (2003).

2) There is high registered cancer cases in Fallujah in comparison with neighboring countries which reflect increase risk of cancers among inhabitants of Al-Fallujah.

3) Variation in incidence rate in different areas of Fallujah Region, the range of incidence rate is from (50 128 cases per 100,000), high incidence in Fallujah Center may reflect the effect of USA army attacks in 2004 and 2005 (Fallujah Battles), it might suggest that the level of risk for the population in different areas is not similar although using data of one year might be not sufficient to detect the true differences in incidence rates and hence differences in exposure to risk factors.

4) Study the details of specific cancers epidemiology in the region should follow this study.

5) Recommendations:

1. Activation of national cancer control program involving (registration, diagnosis, treatment and follow up) to the level of small hospitals to reach the real number of cancer cases in Iraq and to build up a data base for the future studies.

2. Activation of screening programs for early detection of common cancers (breast, colorectal and prostate) to decrease morbidity and mortality of cancer.

3. Broad environmental and medical study about the preventable causes of cancer in Fallujah and all Iraq like (sources of radiation, contaminated water, food and soil, etc).

\section{REFERENCES}

[1] Tadmouri, G. and Al-Sharhan, M. (2012) Cancer in the
United Arab Emirates. Genetic Disorder in the Arab World: United Arab of Emirates. Hamdan Medical Journal, 5, 59-61.

[2] Mousavi, S., Gouya, M., Ramazani, R., Davanlou, M., Hajsadeghin, N. and Seddighi, Z. (2008) Cancer incidence and mortality in Iran. Annals of Oncology, 20, 556563.

[3] Bener, A., Ayub, H., Kakis, R. and Ibrahim, W. (2008) Epidemiology of cancer in Middle East. Asian Pacific Journal of Cancer Prevention.

[4] Busby, C., Hamdan, M. and Ariabi, E. (2010) Cancer, infant mortality and birth sex-ratio in Fallujah Iraq 20052009. International Journal of Environmental Research and Public Health, 7, 2828-2837. doi:10.3390/ijerph7072828

[5] Al-Ali, J. (2006) Cancer trend in Basrah, Iraq. Depleted Uranium-4.5 billion years health risk. www.rauhanpoulustajat.fi/kuvat/Seminarariraporti

[6] Al-Aani, S., Savabieasfahani, M., Tafash, M. and Manduca, P. (2011) Four polygamous families with congenital birth defects from Fallujah Iraq. International Journal of Environmental Research and Public Health, 8, 89-96.

[7] Alanni, S., Tafash, M., Busby, C., Hamdan, M., Blaurock-Busch, E. (2011) Uranium and other contaminants in hair from the parents of children with congenital anomalies in Fallujah, Iraq. Conflict and Health, 5, 15. doi:10.1186/1752-1505-5-15

[8] Al-Attabe, K. (2012) Epidemiological study of 140 cancer cases of inpatient 1994-2000. Misan College of Medicine.

[9] Minstery of Health (2010) Iraqi Cancer Board, Iraqi Cancer Registry Center 2008. Baghdad-Iraq Report.

[10] Bhurgi, Y., Pervez, S., Kayani, N., et al. (2006) Cancer profile of larkana Pakistan (2000-2002). Asian Pacific Journal of Cancer Prevention, 7, 518-521.

[11] Bhurgri, Y., Bhurgri, A., Pervez, S., et al. (2005) Cancer profile of Hyderabad. Pakistan 1998-2002. Asian Pacific Journal of Cancer Prevention, 6, 474-480.

[12] Bray, F., Sankilla, R., Feerlay, J. and Parkin, D. (2002) Estimate of cancer incidence and mortality in Europe in 1995. European Journal of Cancer, 38, 99-166. doi:10.1016/S0959-8049(01)00350-1

[13] Habib, O., Al-Ali, J., Wiswasi, M., Ajeel, N., Al-Asady, O., Khalaf, A. and Al-Mayah, A. (2007) Cancer registration in Basra 2005: Prelimenary Results. Asian Pacific Journal of Cancer Prevention, 8, 187-190.

[14] El-Hag, I., Katchabeswaran, R., Chiedozi, L. and Kollur, S. (2002) Pattern and incidence of cancer in Northern Saudi Arabia. Saudi Medical Journal, 23, 1210-1213.

[15] Amegbor, K., Darre, T., Ayena, K., Padaro, E., Tengue, K., Abalo, A. and Napo-Koura, G. (2011) Cancer in Togo from 1984 to 2008: Epidemiological and pathological aspects of 5251 cases. Journal of Cancer Epidemiology, 2011, Article ID: 319872. doi:10.1155/2011/319872

[16] Shamseddine, A. and Musallam, K. (2010) Cancer epidemiology in Lebanon. Middle East Journal of Cancer, 1, 41-44.

[17] Baban, H. (2012) Bad food increase cancer incidence in 
Kurdistan. www.rudaw.net13149.html

[18] Minstry of Health (2005) Israel National Cancer Registry. http://www.health.gov.II/icr/

[19] Ibrahim, E.M., Al-Mulheim, F.A., Al-Amri, A., Al-Muhana, F.A., Ezzat, A.A., Stwart, P.K., et al. (1998) Breast cancer in the eastern Province of Saudi Arabia. Medical Oncology, 15, 241-247. doi:10.1007/BF02787207

[20] Al-Kayed, S. and Tarawneh, M. (2008) Cancer incidence in Jordan 2004. The Hashemite King of Jordan, Minestery of Health.

[21] Al-Tamimi, T.M., Ibrahim, E.M., Ibrahim, A.M., Al-Bar, A.A., Assuhaimi, S.A. et al. (1997) Cancer in eastern region of Saudi Arabia. A population based study (19871988). Annals of Saudi Medicine, 17, 53-59.
[22] National Cancer Statestics (2008) Jordan Cancer Registery, Cancer Incidence in Jordan. www.khcc.jo.e

[23] Ferlay, J., Bray, F., Pisani, P., Parkin, D. (2004) Globocan 2002: Cancer incidence, mortality and prevalence world wide. IARC Press, Lyon.

[24] Parkin, D., Whelan, S., Farlay, J., Teppo, L., et al. (2002) Cancer incidence in five countries. International Agency for Research on Cancer, Lyon.

[25] Freedum, L., Edwards, B., Ries, L. and Young, J. (1996) Cancer incidence in four member countries (Cyprus Egypt, Israel and Jordan 1996-2001). National Cancer Institute. US Department of Health Human Survices. National Institute of Health. http://mecc.cancer.gov 